\title{
A biobank of primary teeth within the Norwegian Mother and Child Cohort Study (MoBa) per 2014: A resource for the future
}

\author{
Helene Meyer Tvinnereim ${ }^{1}$, Gunvor Bentung Lygre ${ }^{2}$, Kjell Haug ${ }^{3}$, Patricia Schreuder ${ }^{4}$ and Kristin Klock ${ }^{1}$ \\ 1) Department of Clinical Dentistry, Faculty of Medicine and Dentistry, University of Bergen, Norway \\ 2) Dental Biomaterials Adverse Reaction Unit, Uni Health, Uni Research, Bergen \\ 3) Department of Public Health and Primary Health Care, Faculty of Medicine and Dentistry, University of Bergen \\ 4) Norwegian Institute of Public Health \\ Correspondence: Kristin S. Klock, Department of Clinical Dentistry, University of Bergen, Årstadveien 18, NO-5009 Bergen, Norway \\ E-Mail: Kristin.klock@iko.uib.no Telephone: +47 55586596
}

\begin{abstract}
The Norwegian Mother and Child Cohort Study (MoBa) is a prospective population-based cohort study including more than 100,000 pregnancies and following the children through childhood, using questionnaires and collecting biological samples. The aim of MoBa is to test specific aetiological hypotheses by estimating the association between exposure and disease, aiming at prevention. A biobank for exfoliated primary teeth collected from the children participating in MoBa has been established (MoBaTooth Biobank). Samples of tooth tissues from the primary dentition can give information about exposure to toxic and essential elements through foetal life and early infancy. Prenatally and postnatally formed tooth tissues permanently document early exposures unlike other biomarkers, as teeth form incrementally at a known rate. Results from tooth analyses will be coupled to corresponding information in the multiple questionnaires and data from analysis of other biological samples collected by MoBa. Invitations to donate one or more teeth are sent to all mothers/children in the period 2008-2016, when the child is 63/4 years old. By November 2014 21,748 participants had been recorded into the MoBaTooth database donating altogether 28,272 teeth (1.3 teeth per child). The response rate was $24 \%$, but there is a lag of more than one year in the response. Data from the tooth biobank can supply MoBa with important additional information on the uptake of trace elements during foetal life and early infancy. This information can illuminate causal factors of health and disease in the future.
\end{abstract}

This is an open access article distributed under the Creative Commons Attribution Licence, which permits unrestricted use, distribution, and reproduction in any medium, provided the original work is properly cited.

\section{INTRODUCTION}

The Norwegian Mother and Child Cohort Study $(\mathrm{MoBa})$ is a prospective population-based pregnancy cohort study conducted by the Norwegian Institute of Public Health. ${ }^{1}$ Participants were recruited from all over Norway from $1999-2008$, and $40,6 \%$ of invited women consented to participate. The cohort now includes 114,000 children, more than 95,000 mothers and 75,500 fathers. Blood samples were obtained from both parents during pregnancy and from mothers and children (umbilical cord) at birth ${ }^{2}$ (Figure 1). Follow up is conducted by questionnaires at regular intervals and by linkage to national registries. Several substudies are conducting additional collections of data and biological materials. The aim of $\mathrm{MoBa}$ is to test specific aetiological hypotheses by estimating the association between exposure and disease, aiming at prevention. The study is approved for by all relevant Norwegian authorities and has no limitation for follow-up.

A biobank of shed primary teeth collected from the children participating in $\mathrm{MoBa}$ was established in 2008 to supply MoBa with additional biological samples. Human primary teeth have been used as biomarkers of exposure to a number of trace elements, toxic as well as essential. ${ }^{3-9}$ Mineralisation of the tooth buds of primary teeth starts at about the $4^{\text {th }}$ month in foetal life and continues through the first years of childhood. ${ }^{10,11}$ Trace elements, especially those which are bone seeking, are incorporated into tooth substance during tooth formation. ${ }^{12}$ In contrast to mineralised bone tissues, mineralised tooth tissues are very stable; once formed

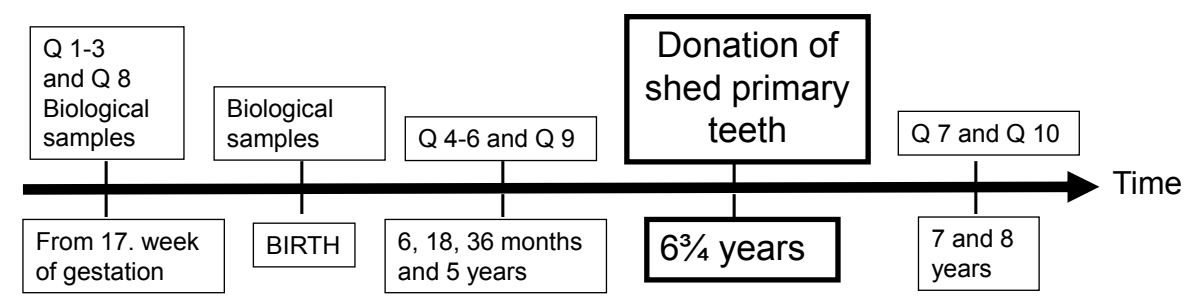

Figure 1. Time line for the questionnaires (Q 1-10), the collection of biological samples within $\mathrm{MoBa}$, and the collection of shed primary teeth to the MoBaTooth Biobank. 
Table 1. Number of child participants (N) within MoBa reaching the age of 63/4 years during the years 2006 to 2016 .

\begin{tabular}{|lccccccccccc|}
\hline Year & 2006 & 2007 & 2008 & 2009 & 2010 & 2011 & 2012 & 2013 & 2014 & 2015 & 2016 \\
\hline $\mathbf{N}$ & 495 & 2,382 & 5,325 & 10,280 & 13,052 & 14,065 & 16,874 & 17,169 & 15,889 & 11,737 & 1,327 \\
\hline
\end{tabular}

they do not remodel. ${ }^{13}$ Unlike other biomarkers, prenatally and postnatally formed tooth tissues permanently document early exposures, as teeth form incrementally at a known rate. This allows for the tracking of elemental fluctuations across months, weeks, and even days. ${ }^{14,15}$

During the last decades we have seen technical as well as methodological improvements of the analysis of mineralised tissues. ${ }^{14,16}$ It is now possible to map the trace element content in tooth tissues to a high precision across the growth lines of the tooth. ${ }^{17,18}$ The growth line mineralised around birth (the neonatal line) may be identified under microscope and tissue samples formed before and after birth may be separated (Figure 2 ). Thus tooth tissues from primary teeth will give information about exposure and nutrition during the most vulnerable time period in life: foetal life and early infancy.

The overall aim of the tooth biobank project (MoBaTooth) is to study the effects of environmental and dietary factors on the health of children in MoBa by combining information from tooth analyses with the comprehensive information available in the questionnaires and other biological samples collected within $\mathrm{MoBa}$ (Figure 3). MoBaTooth will provide a unique opportunity to trace sources of several elements and produce information to estimate associations between exposure and disease. The tooth collection will also give a unique opportunity for further development of primary teeth as biomarkers of environmental exposure, nutrition and disease. In this paper we will present the methods used for sampling of primary teeth to the biobank, including recording, storage and retrieval.

\section{METHODS}

\section{The study population}

The target population is all the 114,000 children participating in MoBa. The study is described in details elsewhere. ${ }^{1}$ The size of the study is based on the fact that many diseases and types of exposures are relatively rare (MoBa protocol: http://www.fhi.no/ morogbarn). Children participating in MoBa are asked to supply one or more shed primary teeth at the age of $63 / 4$ years. In 2006 the first children reached this age and by 2016 the last set of children will reach this age (Table 1).

\section{Collecting teeth}

A letter informing about the MoBaTooth project is sent to all mothers participating in MoBa three months before the child reaches the age of seven years. Participants are asked to donate one or more shed primary teeth and return them in a polypropylene tube supplied to them with a return envelope. The information letter gives a brief description of the purpose of the collection and how parents should treat the tooth/teeth before postage. The teeth should be washed in clean water, without use of detergents, and left to dry over night. The tooth/teeth should then be placed in the tube and put in a small envelope with the child's unique study id-number for identification. The envelope is returned together with a statement of informed consent, signed by the parents. If the child has not yet shed any teeth, or has not kept them when shed, parents are encouraged to send in the next shed tooth in the attached packaging.

EXPOSURE

OUTCOME

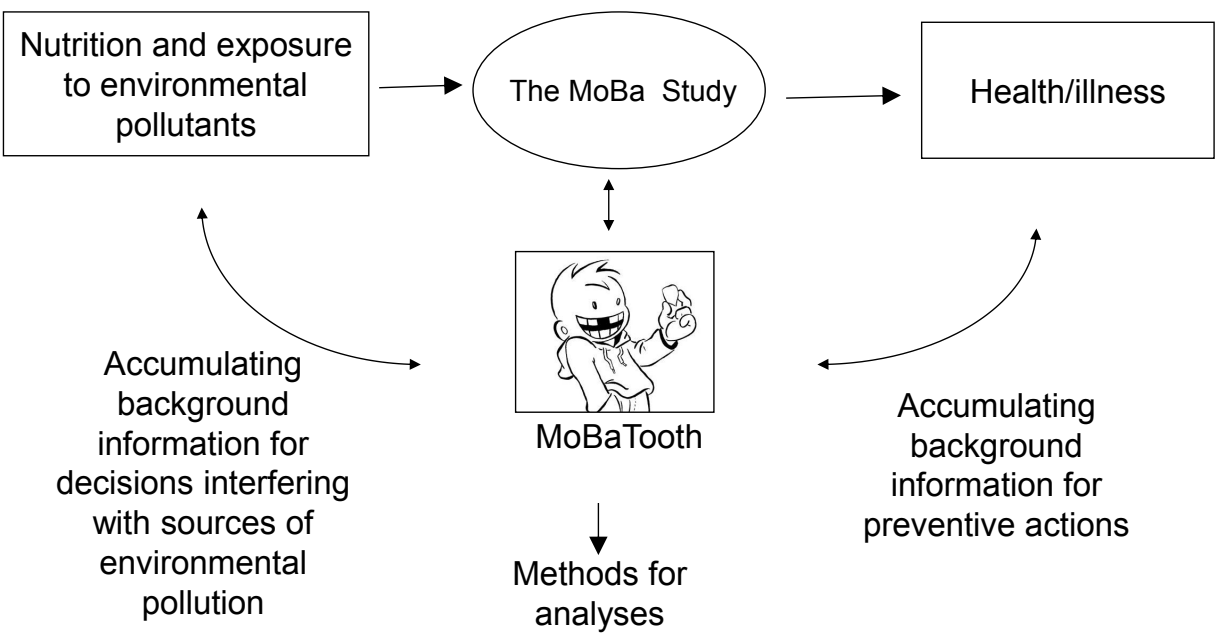

Figure 3. Schematical presentation of information available within $\mathrm{MoBa}$ and MoBaTooth to investigate associations between exposure/nutrition and health outcome. 


\section{Recording of data}

The teeth are recorded in MoBa database before being registered and stored in the biobank of MoBaTooth. The teeth are recorded in an authenticated and encrypted system developed in house. This system enables linkage between results from the analysis of each tooth to corresponding information in the MoBa database.

If a tooth has visible traces of blood, is still humid and/or smells, it is rinsed in distilled water and dried overnight before examination and recording of variables. All teeth collected are handled as possible infectious material. Gloves or tweezers are therefore routinely used when inspecting the teeth.

\section{Variables}

Tooth variables include tooth type (upper and lower central and lateral incisor), caries (score 0-2), attrition/ abrasion of the incisal edge of the tooth crown (score 1-3), and root resorption (score 0-4) (Figure 4, a-d). Internal discoloration of the tooth crown, and enamel hypoplasiahypomineralisation are also recorded when present (score 0-1). It is possible to record free text such as information on excessive calculus, external discolouration, extremely abraded tooth crown etc. Variables are recorded by calibrated personnel using a Luxo magnifier lamp (Bürklin, Oberhaching, Germany). A manual has been developed for the purpose and a test is performed to evaluate the quality of the recording work. ${ }^{19}$

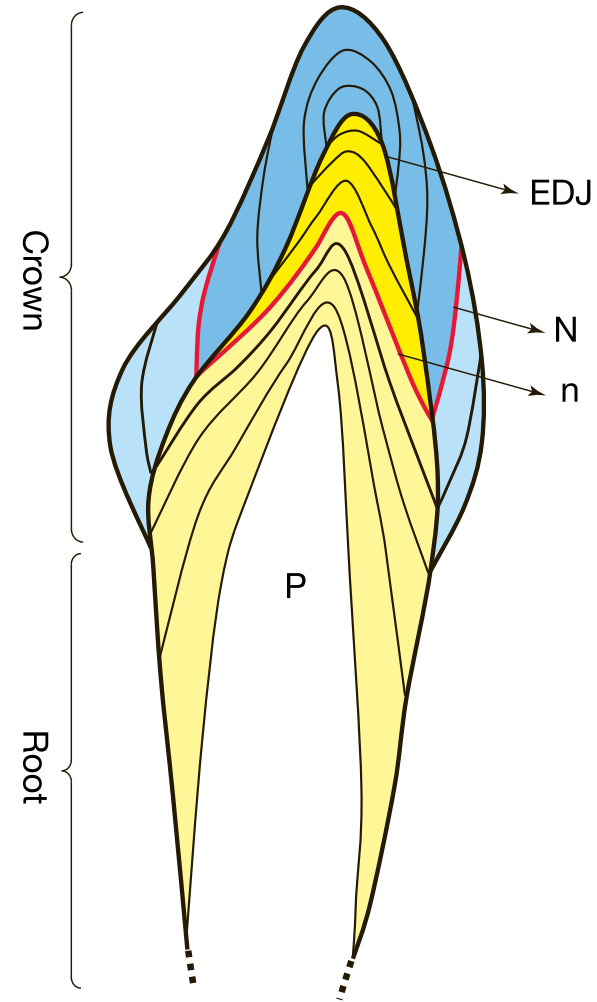

Figure 2. Illustration of a longitudinal sectioned primary incisor in development, showing growth lines in enamel (blue colour) and dentine (yellow). Note the separation of prenatally and postnatally formed enamel and dentine by the neonatal line $(\mathrm{N}=$ neonatal line in enamel, $\mathrm{n}=$ in dentine). The prenatally formed enamel and dentine has the darkest colour. $\mathrm{P}=$ pulp chamber, EDJ = enamel-dentine junction.
A

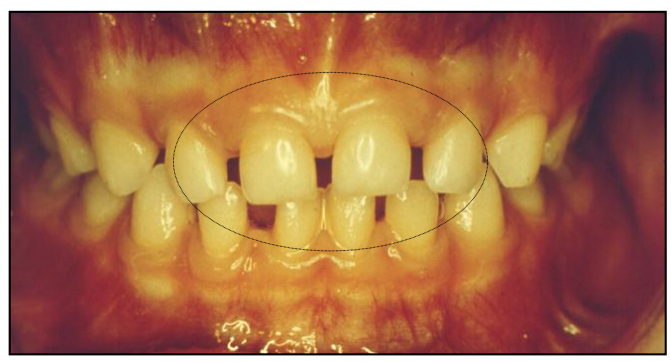

C

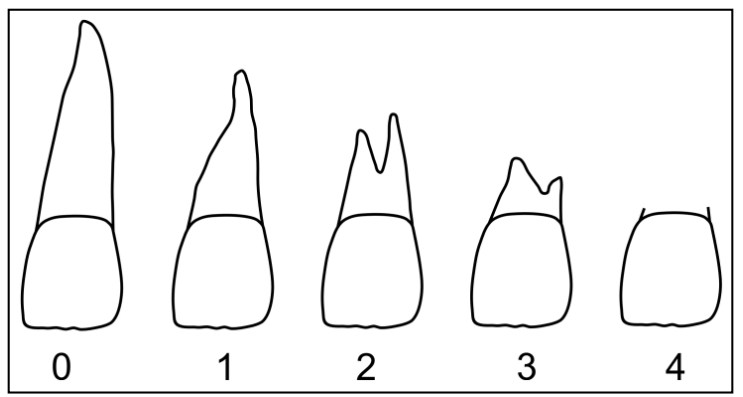

B

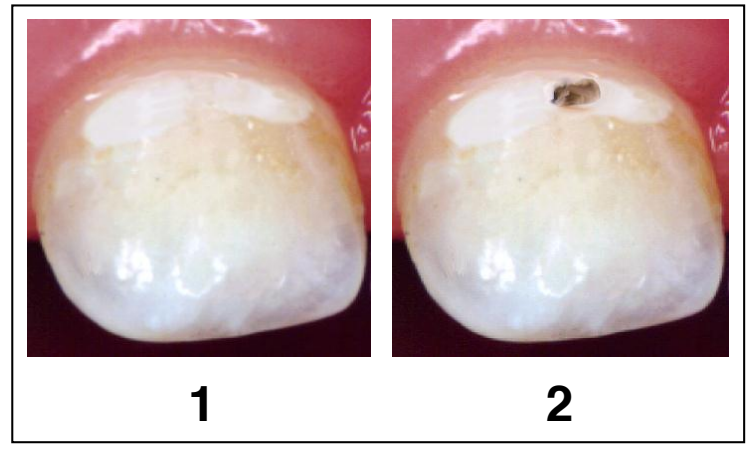

D

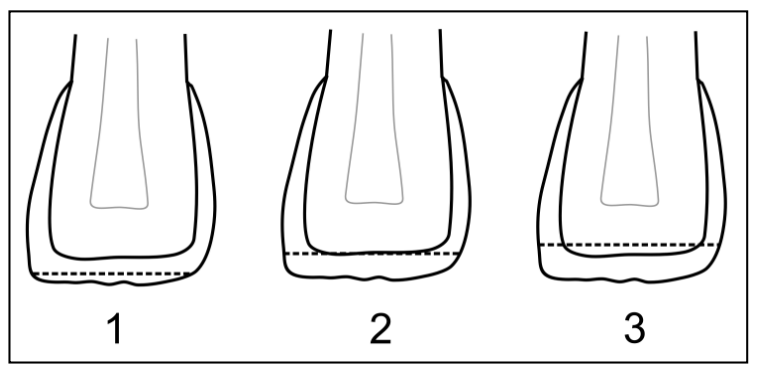

Figure 4. Variables recorded into the database. a: Primary dentition with the actual tooth types encircled. b: Examples of degree of caries $(1=$ enamel caries; 2 = caries with cavitation to dentine*). c: Degree of root resorption $(0-4)$. d: Degree of attrition/abrasion of incisal edge of the tooth crown $(1=$ only in enamel, $2=$ to the enamel-dentin junction, $3=$ further into the dentine). *Courtesy of Prof. Ivar Espelid and Tandläkartidningen (Espelid I, Tveit AB, Mejàre I, Nyvad B. Karies - ny viten eller gamle sannheter? Tandläkartidningen 1997; 89: 19-28.) 


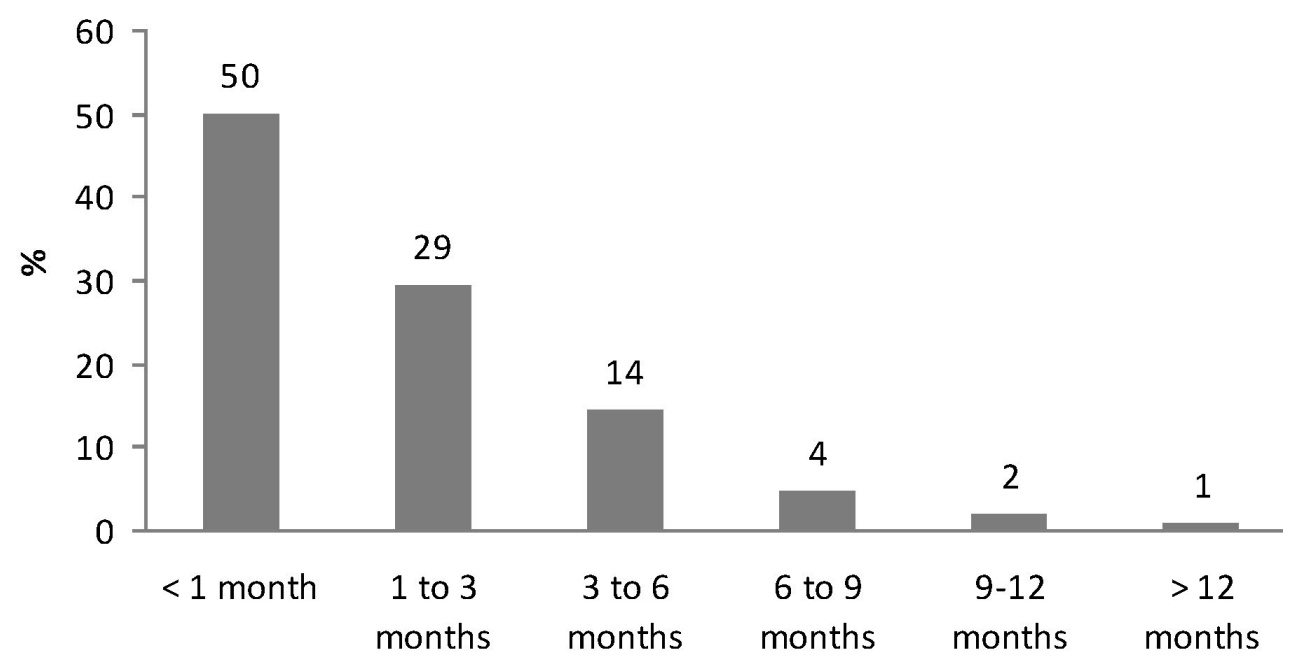

Figure 5. Distribution of respondents in per cent according to the time period from receiving the invitation to participate with teeth in the MoBaTooth-project until the response letter with teeth was received by MoBa.

\section{The biobank}

Handling and storage of the teeth are done in accordance with the Norwegian Biobank Law (http://www. helsedirektoratet.no/loverogregler/lover/biobankloven _7683, captured 25.02.2010). Teeth have almost unlimited shelf life when kept dry at normal room temperature. The teeth are stored in the original package they were received in. Access to the tooth material is given according to current policies in $\mathrm{MoBa}$ (http://www.fhi.no/).

\section{Ethical and legal issues}

The MoBaTooth project has been approved by all relevant institutions in Norway. The database of the tooth biobank gives no access to information about the identity of donors. The participants are informed that they will not receive individual results from tooth analyses. Future findings may be presented on the web page of The Norwegian Institute of Public Health and in the yearly newsletter sent to the participants of MoBa. It is specified that the mother/child at any time can withdraw from participation in the MoBaTooth project and require the teeth destroyed and the data deleted. For each research project intending to use tooth material from the biobank and data/biological samples form $\mathrm{MoBa}$, an application has to be sent to the current regional ethical committee (REK) in Norway for approval of the actual project (http://helseforskning.etikkom.no).

\section{RESULTS}

\section{Status to date}

A total of 28,272 primary teeth, representing 21,748 children, had been registered into the MoBaTooth database by November 2014. The response rate was about $24 \%$ of the participants that had received an invitation to donate teeth by this point of time. The number of teeth offered per donor varied from one to seven teeth with a mean of 1.3 per child. There was no difference in gender distribution. The response time varied from a few days to more than one year (Figure 5).

Altogether $44.8 \%$ were upper front teeth, $52.7 \%$ were lower front teeth, and $2.5 \%$ were classified as uncertain tooth type. Caries lesions were found in $1.2 \%$ of the teeth, $92 \%$ had more than $2 / 3$ of the root resorbed, $55 \%$ of the teeth were markedly worn at the incisal edge, $1.7 \%$ had internal discoloration and $0.4 \%$ of the teeth had obvious areas of hypoplasia/hypomineralisation on the enamel surface.

The majority of the teeth were clean and dry. Only a small number showed traces of blood or other soft organic residuals on the surface or were humid or bad smelling. Calculus at the surface was frequently seen.

\section{DISCUSSION}

$\mathrm{MoBa}$ is a cohort study where the individual is recruited to the study prior to the onset of the disease/dysfunction that is to be studied. Linkage to other Norwegian health registries (e.g. Medical Birth Registry or Cancer Registry) or exposure registry (National census data) will enable new data sets to be generated simply and effectively. ${ }^{1}$

The collected primary teeth will constitute a biobank in the MoBa system, and the information from analyses of variables will supplement to the vast amount of information in the main study. Many of the subprojects will be based on the cohort design of the main project. When teeth samples are being analysed, the relevant design will be a nested case-control study. This involves identifying a sample of subjects that have developed the disease or dysfunction to be studied and selecting controls that have not developed the disease. Trace element concentrations will be measured in teeth for both groups to look for differences.

\section{Selection to MoBa}

Selection of participants to the main study is described in the MoBa protocol (http://www.fhi.no/morogbarn). 
The population was all pregnant women. The most important selection is linked to a lack of willingness to participate. A participation rate of about $40 \%$ is acceptable since the main purpose is to calculate the associations between exposure and illness. MoBa is not designed for studies of incidence and prevalence. The incidence of caries of $1.2 \%$ found within the tooth collection may thus not be representative for the Norwegian child population, as incidence of caries varies for instance by the parents' educational level. ${ }^{20}$

\section{Selection to MoBaTooth}

The relatively low response rate $(24 \%)$ may indicate that some of the children had not shed teeth by the time the parents received the letter from the MoBaTooth project, or they may have lost them or thrown them away. The response rate may increase during the collection period as there is a delay in the response. Approximately half of the donors responded within the first month while some responded after one year (Figure 5). Many of the invited children/mothers might prefer to keep the teeth as valuable mementos from childhood.

\section{Why ask for teeth at about seven years of age?}

We decided to collect primary front teeth which are the first teeth to be developed and shed. More than two thirds of the crown of front teeth is developed before birth. The crown therefore consists of a large bulk of prenatally formed tooth substance. Furthermore, the front teeth are less often attacked by caries than the molars. The front teeth are commonly shed in the period between 5 and 9 years, the central incisors first, followed by the laterals. ${ }^{21}$ Collecting teeth from the MoBa-children at the age of $63 / 4$ years was chosen for practical reasons.

In the invitation letter we ask for shed primary teeth without specifying a certain tooth type. This was done to make it easier for the participants. On the other hand, it would have be an advantage to collect the same tooth type from all the participants. The central incisors of the upper jaw would be the preferred ones, as these teeth are the largest that are shed at the actual age, thus providing more material for the tooth analyses. So far $29.7 \%$ of the teeth collected are central incisors from the upper jaw.

\section{Handling of the teeth}

The parents are asked to wash the teeth in clean water without detergents. The teeth are not treated further before storage, thus avoiding the introduction of any chemicals or high temperature regime that might interfere with future study methods. The tooth material must therefore be treated as potentially infectious.

\section{Registering of tooth variables into the database}

The variables selected to be recorded into the database for each tooth were primarily information describing available material in the specific tooth. A non-carious tooth contains more tooth substance representing the tooth formation period than a carious tooth, as carious lesions are demineralised and may exchange elements and substances with the oral cavity. ${ }^{22}$ Incisal wear of the tooth crown gives information on the degree of loss of the earliest formed tooth substance in the incisal region, and degree of root resorption gives an estimate of root substance available.

The more seldom incidence of internal discolouration indicates former bleeding in the pulp chamber, as traces of blood have been integrated into the peripulpal dentine, giving rise to elements not originating from the period of tooth formation. Thus, decolourised teeth are not preferred.

\section{Storing of the teeth}

In determining the logistics of the tooth biobank, issues of optimal storage of the teeth were balanced by the costs. It was decided to store the teeth in dry condition at room temperature. Mineralized tooth tissues can be stored indefinitely in this way. Still, storing the teeth in freezers may prevent the teeth from drying out and break into pieces. Furthermore, freezing of the teeth may possibly prevent the disintegration of persistent organic pollutants (POPs) that might have been integrated into the organic parts of the tooth tissues during tooth development. ${ }^{23}$ In the "Avon Longitudinal Study of Parent and Child Study (ALSPAC)"24 primary teeth have been stored in freezers in the same way as the other biological samples collected (personal information from Amanda Carmichael, Deputy Director, ALSPAC). At present, analytical methods for measuring POPs in mineralized tooth tissues are not available as far as we know, but may appear in future research.

\section{Future perspectives}

Tooth tissues are the most chemically stable tissues in the body and can be stored indefinitely at room temperature when kept dry. The collected teeth will be stored and made available to scientists in the future. The likely development of new and improved methods will offer the opportunity to investigate new hypothesis of possible associations between exposure and outcome as health/illness of nutritional and environmental factors.

\section{CONCLUSION}

The biobank of primary teeth will supply MoBa with important additional information on the uptake of trace elements and substances during foetal life and early infancy. This information can illuminate causal factors of health and disease in the future.

\section{ACKNOWLEDGEMENTS}

The original manuscript was first published in Paediatric and Perinatal Epidemiology 2012; 26 (3): 264-71. This version has updated results.

The donation of teeth, other biological material and questionnaire data from MoBa participants are gratefully acknowledged. The MoBaTooth project has been supported by grants from the University of Bergen through funding form Department of Clinical Dentistry, the Norwegian Research 
Funding, the Meltzer University Fund, the Norwegian Dental Depot Fund and the Dr. Einar Bergesen Endowment, Bergen. Thanks to Professors Rune Eide and Nils Roar Gjerdet, Department of Clinical Dentistry - Biomaterials, UoB, for their support during the establishment period of the biobank, data engineer Ole Martin Kvinge and adviser Marianne
Bjørnen at the Norwegian Institute of Public Health for developing the data base for MoBaTooth and administering the practical part of the collection of the teeth, respectively; and to engineer Odd Johan Lundberg and research technician Randi Sundfjord at Department of Clinical Dentistry assisting in the administration of the biobank.

\section{REFERENCES}

1. Magnus P, Irgens LM, Haug K, Nystad W, Skjaerven R, Stoltenberg C. Cohort profile: The Norwegian Mother and Child Cohort Study (MoBa). Int J Epidemiol 2006; 35: 1146-1150.

2. Rønningen KS, Paltiel L, Meltzer HM, Nordhagen R, Lie KK, Hovengen R, et al. The biobank of the Norwegian Mother and Child Cohort Study: a resource for the next 100 years. Eur J Epidemiol 2006; 21: 619-625.

3. Sharon IM. The significance of teeth in pollution detection. Perspect Biol Med 1988; 32: 124-131.

4. Blanusa M, Ivicic N, Simeon V. Lead, iron, copper, zinc and ash in deciduous teeth in relation to age and distance from a lead smelter. Bull Environ Contam Toxicol 1990; 45: 478-485.

5. Tvinnereim HM, Eide R, Riise T, Wesenberg GR, Fosse G, Steinnes E. Lead in primary teeth from Norway: changes in lead levels from the 1970s to the 1990s. Sci Total Environ 1997; 207: 165-177.

6. Mangano JJ, Gould JM, Sternglass EJ, Sherman JD, McDonnell W. An unexpected rise in strontium-90 in US deciduous teeth in the 1990s. Sci Total Environ 2003; 317: 37-51.

7. Brown CJ, Chenery SR, Smith B, Mason C, Tomkins A, Roberts GJ, et al. Environmental influences on the trace element content of teeth - implications for disease and nutritional status. Arch Oral Biol 2004; 49: 705717.

8. Dolphin AE, Goodman AH. Maternal diets, nutritional status, and zinc in contemporary Mexican infants' teeth: Implications for reconstructing paleodiets. Am J Phys Anthropol 2009; 140: 399-409.

9. Tvinnereim HM, Fantaye W, Isrenn R, Bjorvatn K, Melaku Z, Teklehaimanot R. Lead levels in primary teeth in children from urban and rural areas in Ethiopia. Ethiopian Med J 2011; 49: 61-66.

10. Nanci A. Ten Cate's Oral Histology: Development, Structure, and Function, 7th edn. St Louis: Mosby, 2008: 287.

11. Berkovitz B, Holland G, Moxham B. Oral Anatomy, Histology and Embryology, 4th edn. London: Mosby, 2009.

12. Blumenthal NC. The in vitro uptake of trace elements by hydroxyapatite. In: Priest ND, Van De Vyver FL, eds. Trace metals and fluoride in bones and teeth. Boca Raton: CRC Press, 1990: 307-314.

13. Steenhout A. Kinetics of lead storage in teeth and bones: An epidemiological approach. Arch Environ Health 1982; 37: 224-230.

14. FitzGerald CM, Saunders SR. Test of histological methods of determining chronology of accentuated striae in deciduous teeth. Am J Phys Anthropol 2005; 127: 277-290.

15. Arora M, Kennedy BJ, Elhlou S, Pearson NJ, Walker DM, Bayl P, et al. Spatial distribution of lead in human primary teeth as a biomarker of pre- and neonatal lead exposure. Sci Total Environ 2006; 371: 55-62.

16. Webb E, Amarasiriwardena D, Tauch S, Green EF, Jones J, Goodman AH. Inductively coupled plasma-mass (ICP-MS) and atomic emission spectrometry (ICP-AES): Versatile analytical techniques to identify the archived elemental information in human teeth. Microchem $J$ 2005; 81: 201-208.

17. Goodman AH, Dolphin AE, Amarasiriwardena DRK, Backstrand J, Reid JJ. Tooth rings: Dental enamel as a chronological biomonitor of enamel absorption from pregnancy to adoloscence. J Children's Health 2003; 1: 203-214.

18. Dolphin AE, Goodman AH, Amarasiriwardena DD. Variation in elemental intensities among teeth and between pre- and postnatal regions of enamel. Am J Phys Anthropol 2005; 128: 878-888.

19. Tvinnereim HM, Klock K, Lygre GB, Schreuder P, Haug K. Biobanking primary teeth collected from children within the Norwegian Mother and Child Cohort Study. CELCE2010 - Longitudinal and Life Course Studies: International Journal. Cyprus: Longview, 2010: 94.

20. Thomson WM, Poulton R, Milne BJ, Caspi A, Broughton JR, Ayers KM. Socioeconomic inequalities in oral health in childhood and adulthood in a birth cohort. Community Dent Oral Epidemiol 2004; 32: 345-353.

21. Schour I, Massler M. The development of human dentition. J Am Dent Assoc 1941; 28: 1153-1160.

22. Bercovitz K, Laufer D. Carious teeth as indicators to lead exposure. Bull Environ Contam Toxicol 1993; 50: 724-729.

23. Jan J, Sovcikova E, Kocan A, Wsolova L, Trnovec T. Developmental dental defects in children exposed to PCBs in eastern Slovakia. Chemosphere 2007; 67: S350-354.

24. Golding J, Pembrey M, Jones R. ALSPAC - the Avon Longitudinal Study of Parents and Children. I. Study methodology. Paediatr Perinat Epidemiol 2001; 15: 74-87. 